\title{
Etrasimod, an Oral, Selective Sphingosine 1-phosphate Receptor Modulator Improves Skin Inflammation in a Contact Hypersensitivity Model of Dermatitis
}

\author{
Catherine M. Crosby, H. Kiyomi Komori, John W. Adams
}

Arena Pharmaceuticals, San Diego, CA

\section{INTRODUCTION}

Introduction:

Etrasimod (APD334) is an orally administered, selective sphingosine 1-phosphate

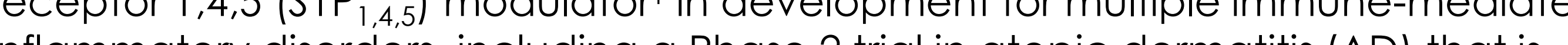
expected to be initioted in 2019 SIP is a cell surfoce $G$ protein-coupled receptor (GPCR) that has been shown to regulate lymphocyte egress from lymph nodes ${ }^{2}$ and dendritic cell trafficking

Goal of Study:

The goal of this pre-clinical study was to evaluate the effect of etrasimod on skin inflammation and immune cell cellularity in the fluorescein isothiocyanate (FITC)induced dermatitis mouse model.

Overall Conclusions:

Etrasimod effectively reduced ear skin inflammation and dermatitis in FITC-induced expansion of immune cells in the draining lymph node and ear skin Notably, the dosedependent reduction of immune cells in ear skin correlated with improvements in disease. This data encourages further study of etrasimed as a novel therapy for $A D$.

\section{RESULTS}

Etrasimod Dose-Dependently Reduced Ear Skin Thickness and Histopathological Score

Ear Thickness Change
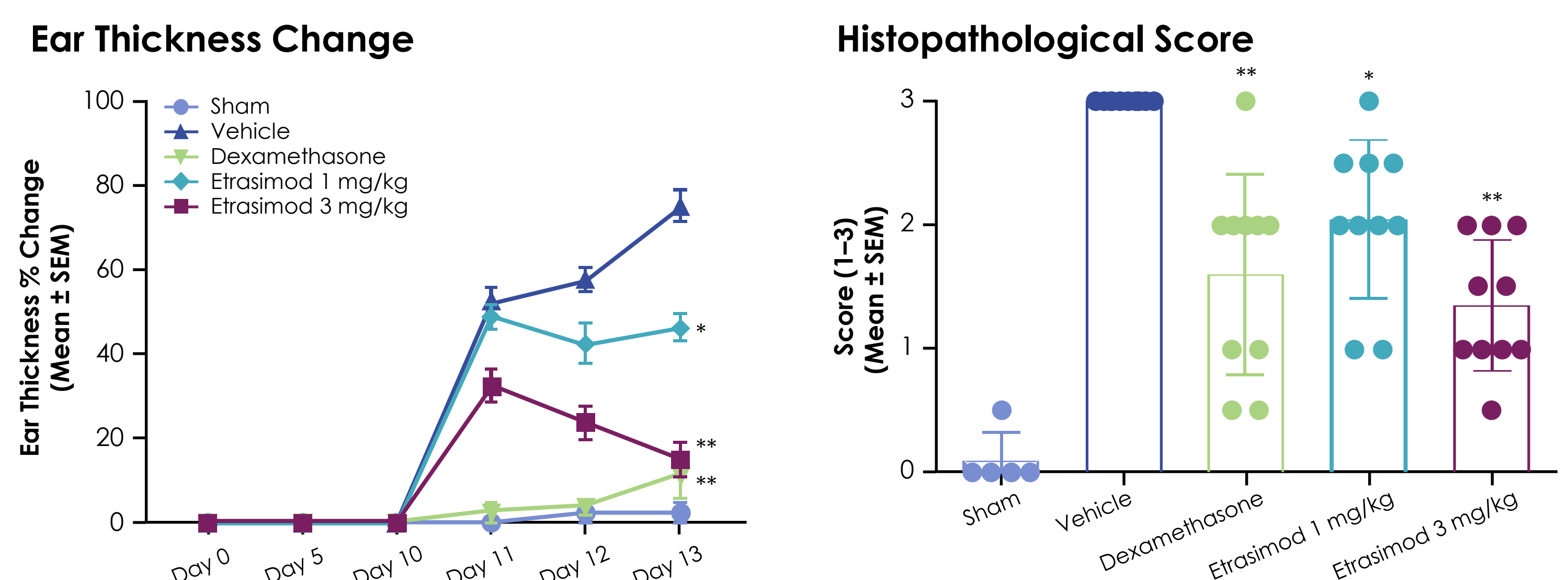

Figure 1A: Etrasimod treatment resulted in a significant, dose-dependent reduction in ear thickness. On Day 13, the difference in ear thickness between were not significantly different.

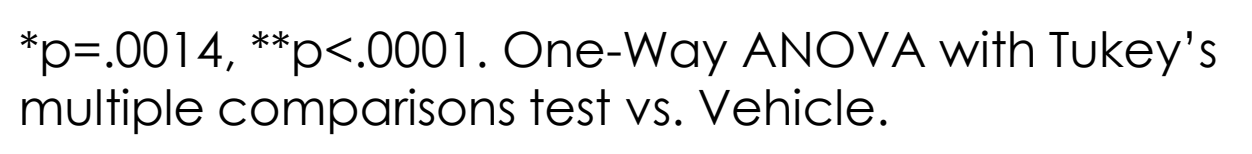

Figure 1B: Etrasimod treatment resulted in a significant, dose-dependent reduction in histopathological score. There was no significant difference between etrasimod $3 \mathrm{mg} / \mathrm{kg}$ and dexamethasone.

\section{SENSIIIZAAIION Day 2: Inguinal Draining Lymph Node}

Total Immune Cells and Subsets Similarly Increased in the Inguinal Lymph Node in All Treatment Groups
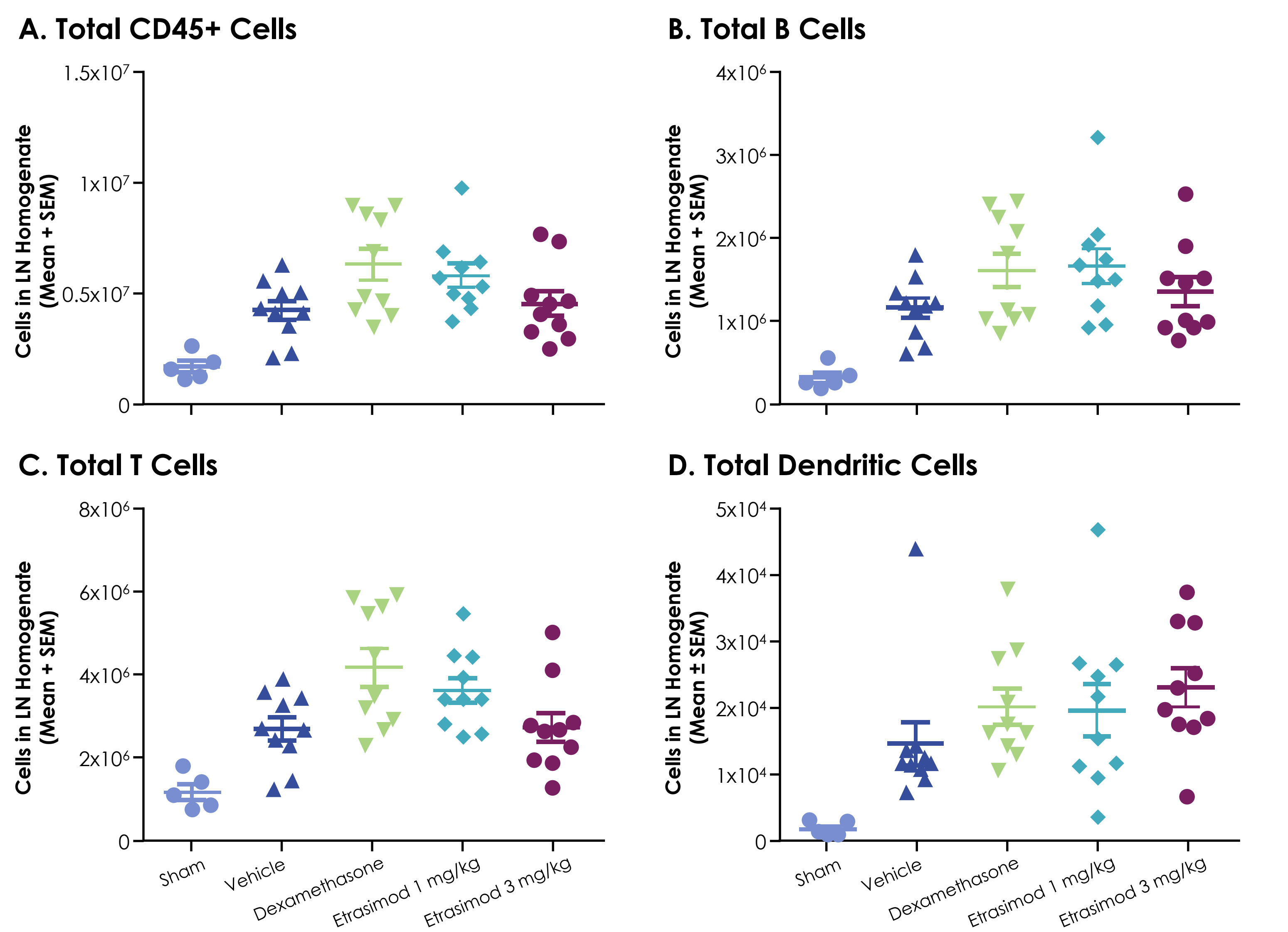

Figure 2: Total A) CD45+ cells, B) B cells, C) T cells, and D) dendritic cells significantly increased upon sensitization. Dexamethasone and etrasimod (1 and $3 \mathrm{mg} / \mathrm{kg}$ ) had no significant impact on the increased cellularity in the lymph nodes.

\section{CHALLENGE Day 13: Blood}

Etrasimod Reduced Circulating White Blood Cells and Lymphocyte Frequency

A. White Blood Cell Count

Lymphocyte Frequency of WBC

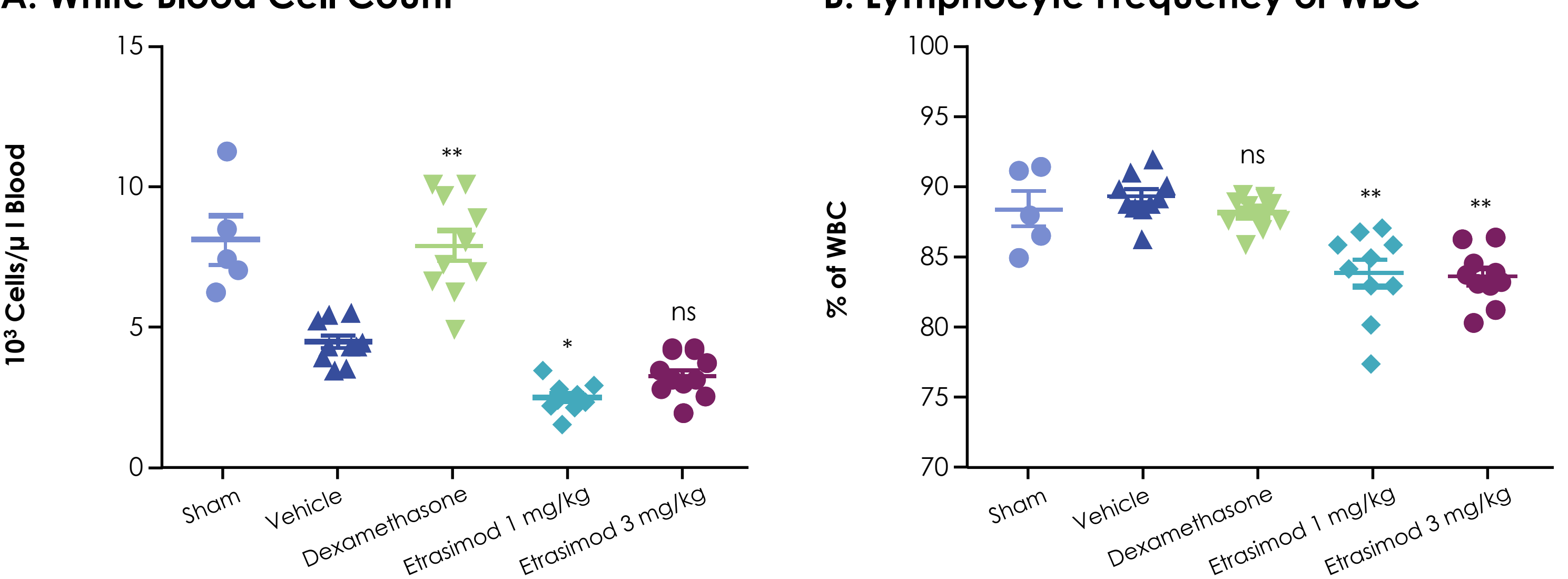

\section{METHODS}

Experimental Design and Treatment Groups

Beginning on Day -1 , female BALB/c mice were orally dosed daily with the indicated treatments in phosphate buffered saline (PBS). Etrasimod doses in vivo studies.

On Days 0 and 5, mice were sensitized with $1 \%$ fluorescein On Dars 0 and 5, mice we sensized on Days 11,12 , and 13 .

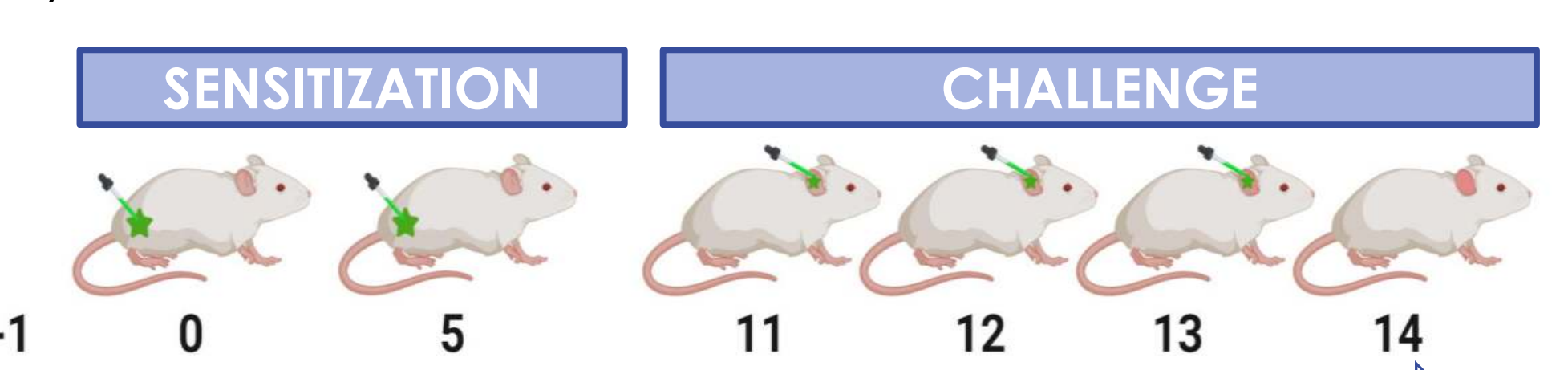

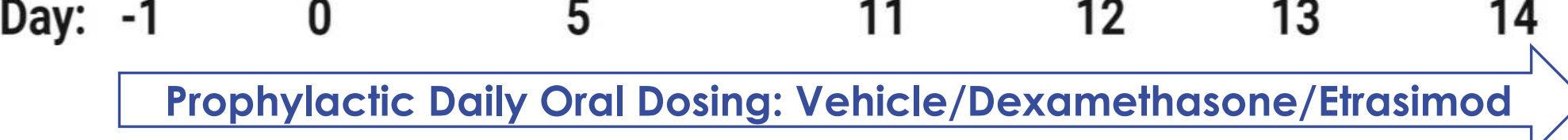

\begin{tabular}{|c|c|c|c|}
\hline $\begin{array}{l}\text { Treatment } \\
\text { Group }\end{array}$ & $\begin{array}{c}\text { Time } \\
\text { Course } \\
\text { Analysis } \\
\end{array}$ & $\begin{array}{c}\text { Day } 2 \\
\text { Analysis } \\
\text { (50\% of mice) }\end{array}$ & $\begin{array}{c}\text { Day } 13 \\
\text { Analyses } \\
\text { (50\% of mice) }\end{array}$ \\
\hline Sham $(n=10)$ & \multirow{5}{*}{$\begin{array}{l}\text { Ear } \\
\text { thickness } \\
\text { measured } \\
\text { using a dial } \\
\text { caliper }\end{array}$} & \multirow{5}{*}{$\begin{array}{l}\text { Inguinal } \\
\text { lymph } \\
\text { node } \\
\text { cellularity } \\
\text { analyzed } \\
\text { by flow } \\
\text { cytometry }\end{array}$} & \multirow{5}{*}{$\begin{array}{l}\text { - Blood analyzed by } \\
\text { complete blood count } \\
\text { (CBC) with differential } \\
\text { - Cervical lymph node } \\
\text { cellularity analyzed by } \\
\text { flow cytometry } \\
\text { - One ear fixed, stained } \\
\text { with Hematoyylin \& Eosin, } \\
\text { and histologically scored } \\
\text { - One ear enzymatically } \\
\text { digested, homogenized, } \\
\text { and cellularity analyzed } \\
\text { by flow cytometry }\end{array}$} \\
\hline $\begin{array}{l}\text { Vehicle Control } \\
\text { (PBS) }(n=20)\end{array}$ & & & \\
\hline $\begin{array}{l}\text { Dexamethasone } \\
1 \mathrm{mg} / \mathrm{kg}(\mathrm{n}=20)\end{array}$ & & & \\
\hline $\begin{array}{l}\text { Etrasimod } \\
1 \mathrm{mg} / \mathrm{kg}(\mathrm{n}=20)\end{array}$ & & & \\
\hline $\begin{array}{l}\text { Etrasimod } \\
3 \mathrm{mg} / \mathrm{kg}(\mathrm{n}=20)\end{array}$ & & & \\
\hline
\end{tabular}

Etrasimod Reduced Dendritic Cell Etrasimod Similarly Reduced T Cells, B Cells, and Eosinophils in the Influx Into the Cervical Lymph Node Cervical Lymph Node
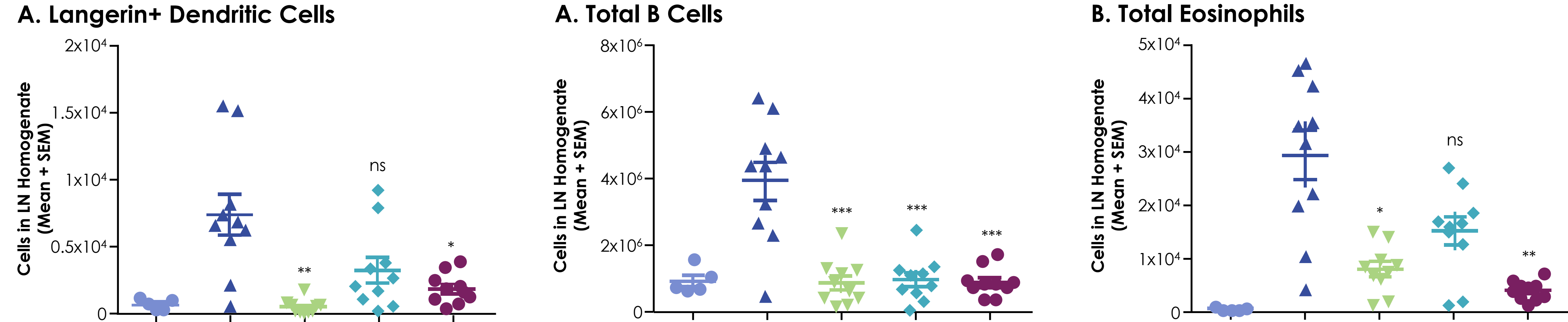

B. Langerin- Dendritic Cells

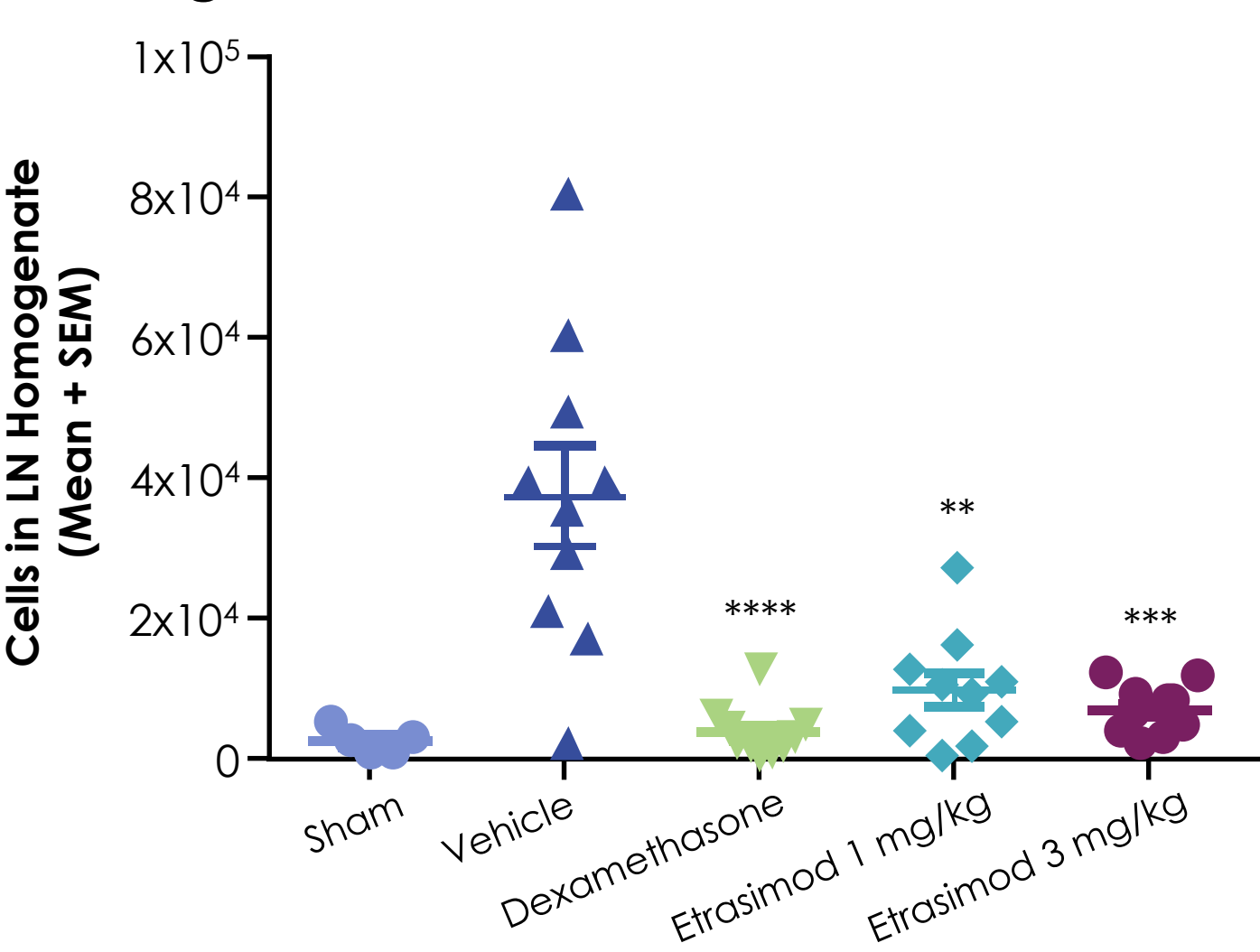

C. Total $\alpha \beta$ T Cells

D. CD69+ $\alpha \beta$ T Cells
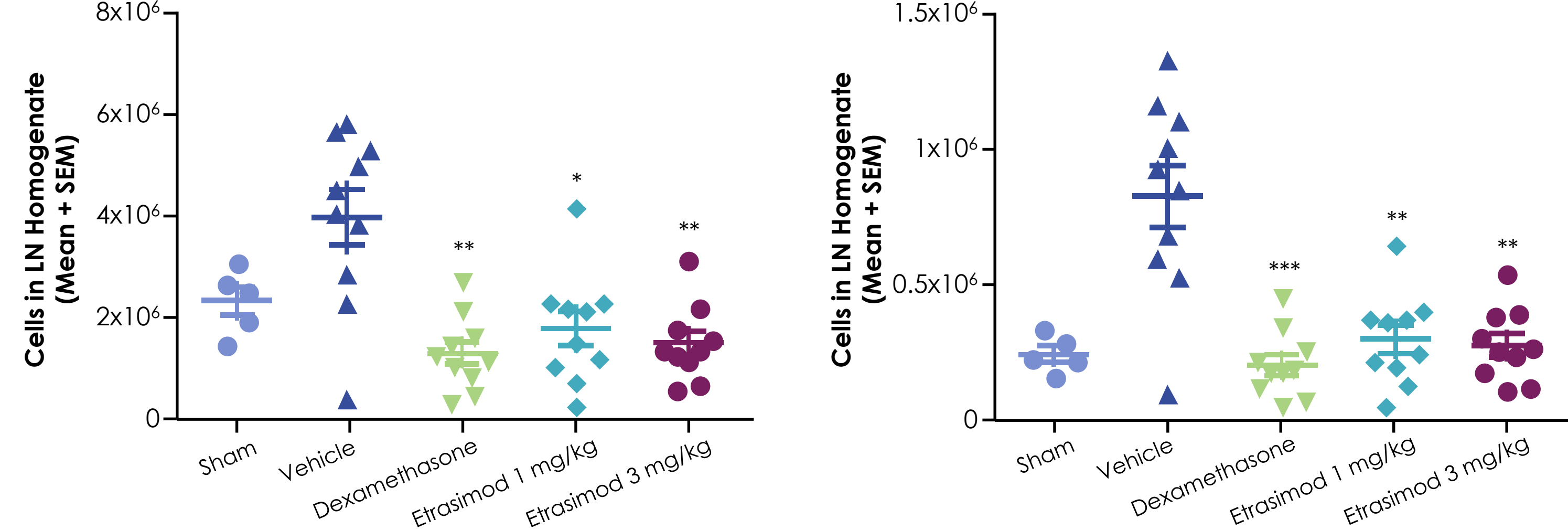

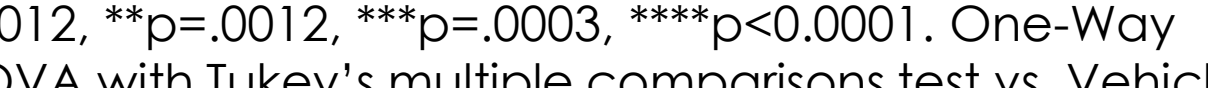

Figure 4: Etrasimod 1 and $3 \mathrm{mg} / \mathrm{kg}$ reatments similarly reduced the tanticking of both $A$ ) Langerint and $B$

Figure 5: Etrasimod 1 and $3 \mathrm{mg} / \mathrm{kg}$ treatments reduced the expansion of A) B cells and B) Eosinophils to a similar magnitude as dexamethasone. Etrasimod similarly reduced the $C$ ) expansion and D) activation of $\alpha \beta T$ cells.

\section{CHALLENGE Day 13: Ear Skin}

In the Ear Skin, Etrasimod Reduced T Cells, B Cells, and Eosinophils in Dose-dependent Manner

A. Total B Cells

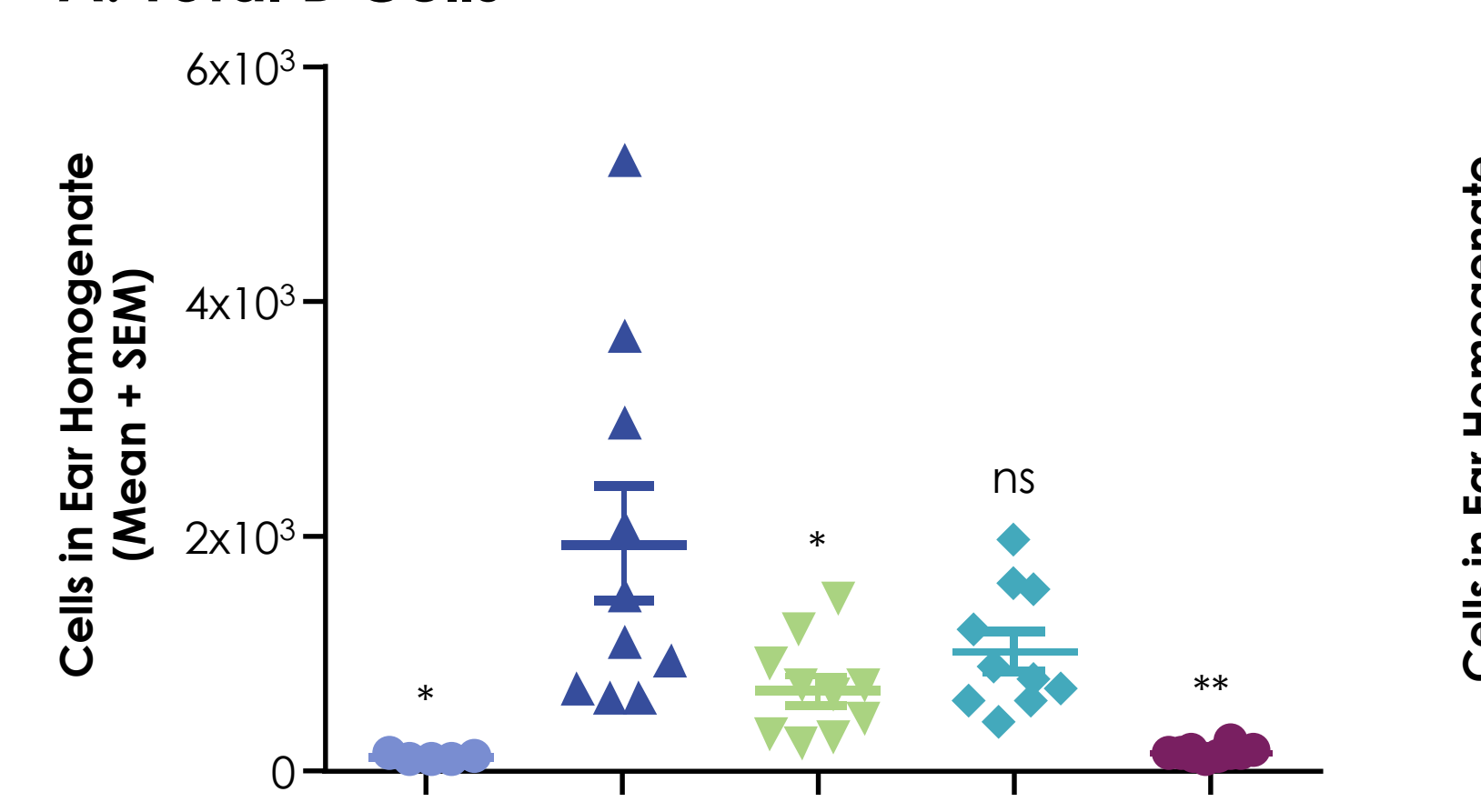

C. Total $\alpha \beta$ T Cells

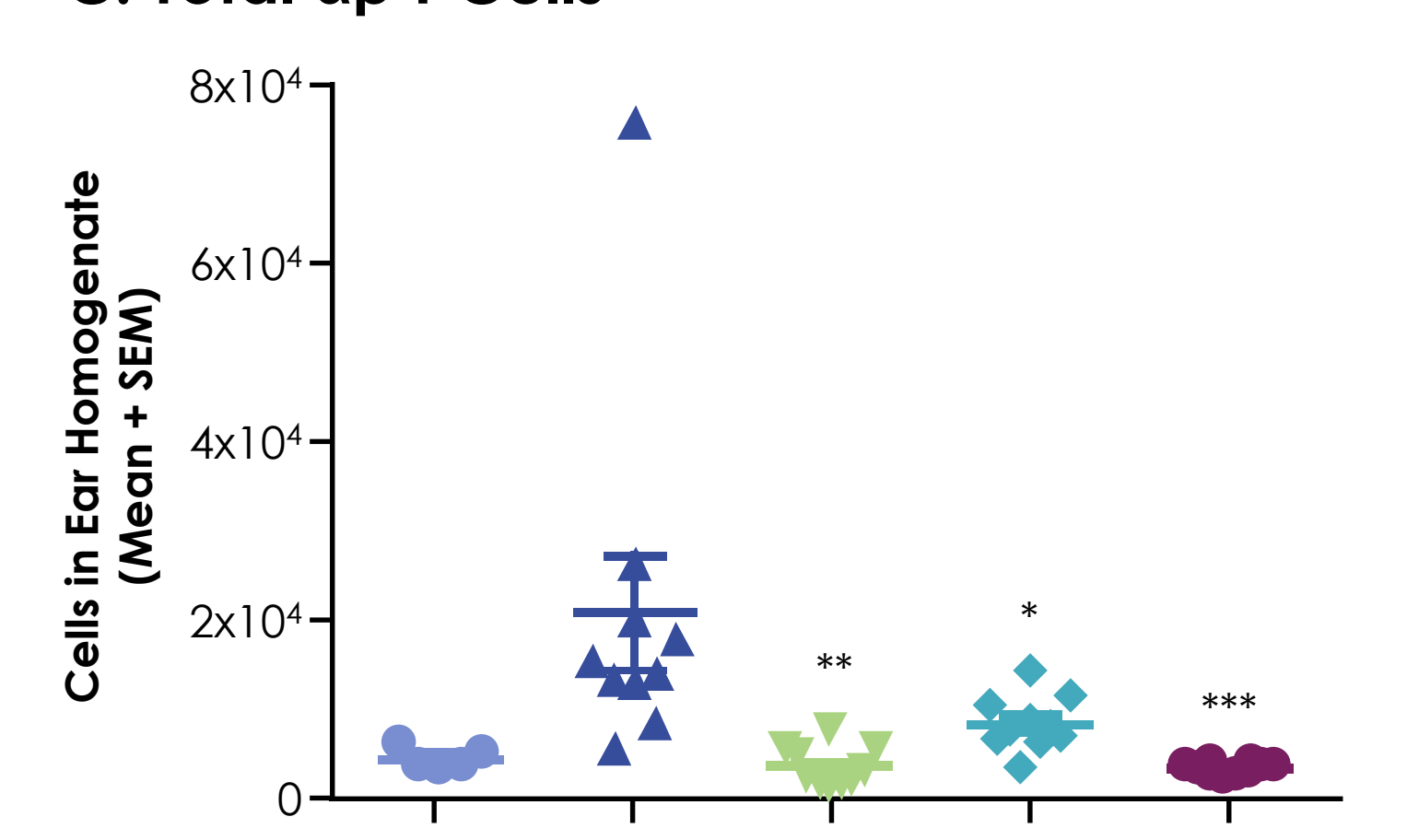

E. CLA+ $\alpha \beta$ T Cells Ear Skin

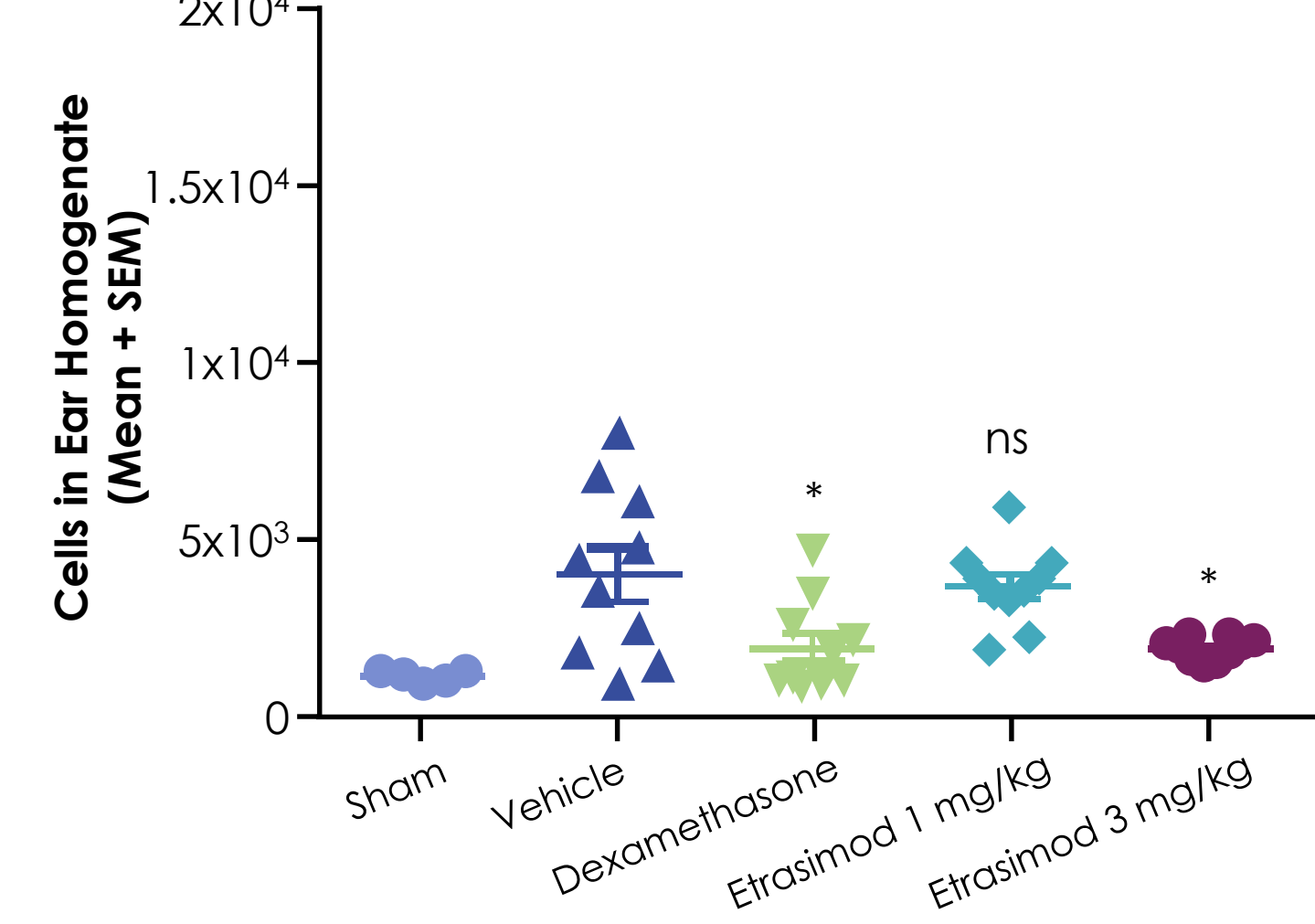

B. Total Eosinophils

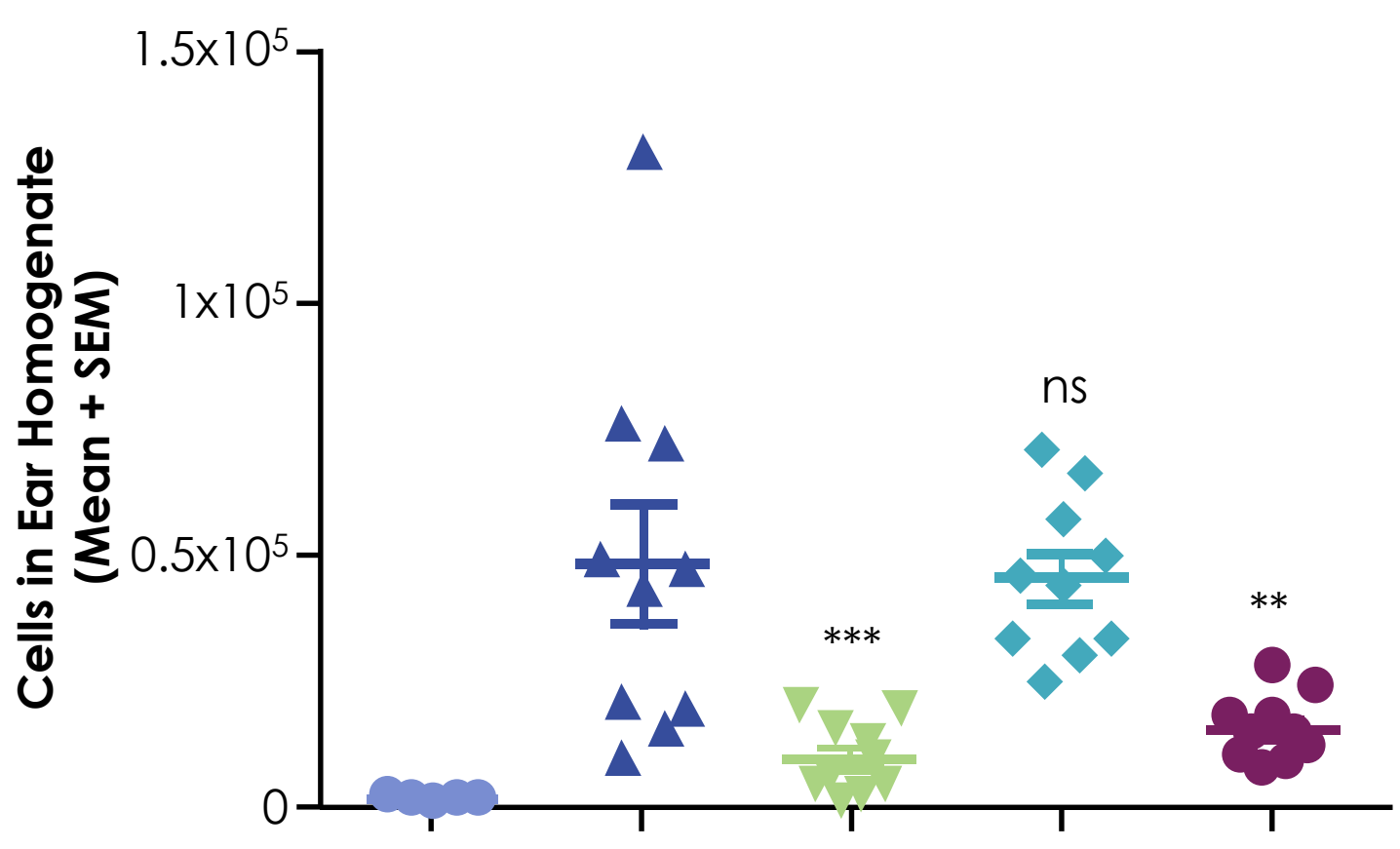

D. CD69+ $\alpha \beta$ T Cells

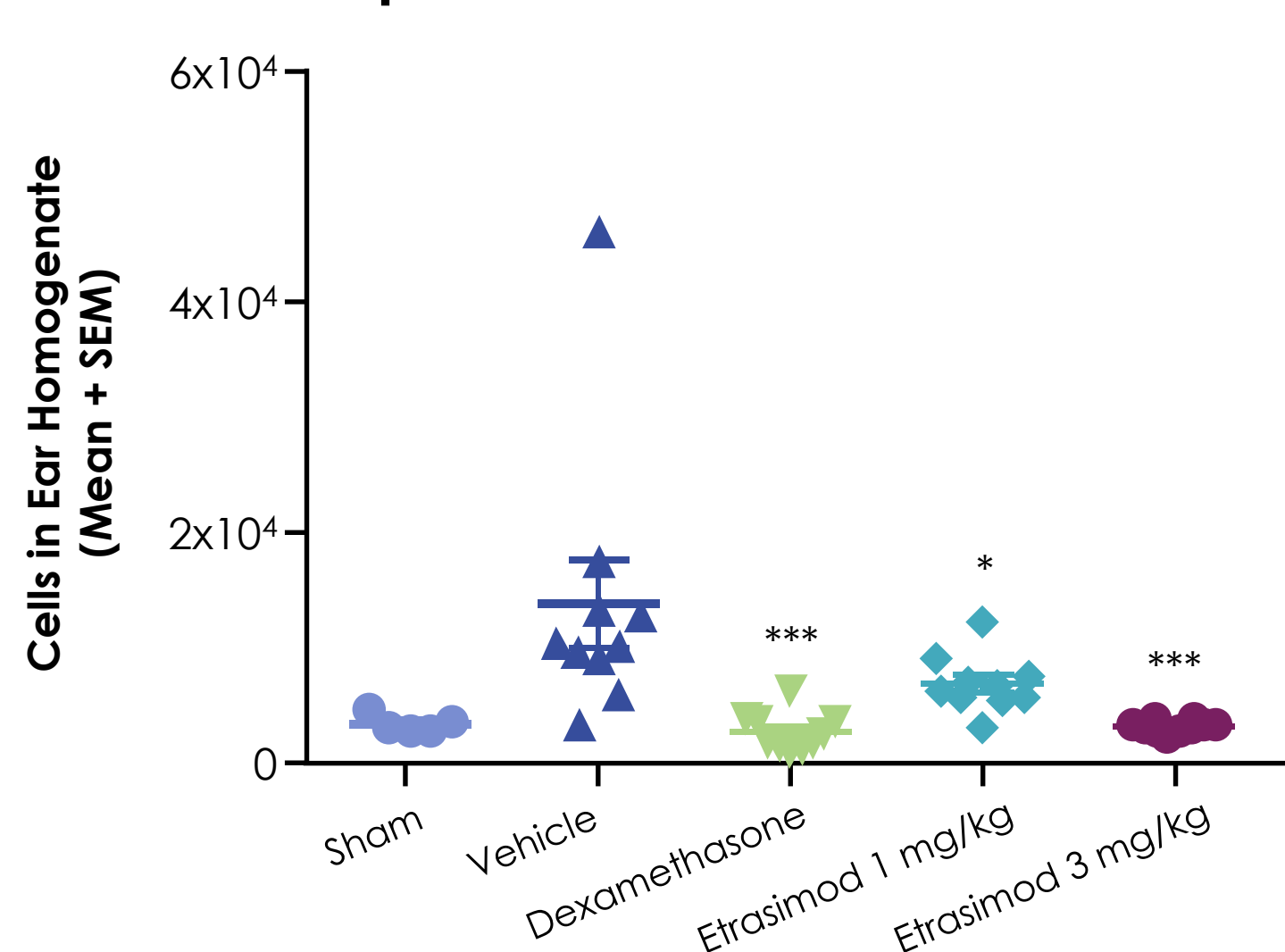

${ }^{*} p<0.05,{ }^{* *} p<.008, * * * p<.001$. One-Way ANOVA with Tukey's

Figure 6: Etrasimod 1 and $3 \mathrm{mg} / \mathrm{kg}$ doses significantly reduced the activation and expansion of total a $\beta$ T cells, including in the and skin $(C-$ E) in $3 \mathrm{mg} / \mathrm{kg}$ treatment significantly reduced eosinophils in the skin.

\section{REFERENCES}

\section{CONCLUSIONS}

Sensitization Phase

- Dendritic Cells, T cells, and B cells draining lymph node in the inguinal etrasimod had no effect on the number of cells. This suggests the sensitization phase was relatively intact in this model.

Challenge Phase

- Etrasimod treatment reduced the trafficking of dendritic cells to the cervical draining lymph node. The effect was greater in the $3 \mathrm{mg} / \mathrm{kg}$ v $1 \mathrm{mg} / \mathrm{kg}$ doses.

- In the cervical draining lymph node. etrasimod reduced T cells, B cells, and eosinophils. The effect was similar with the $1 \mathrm{mg} / \mathrm{kg}$ and $3 \mathrm{mg} / \mathrm{kg}$ doses for served with the $3 \mathrm{mg} / \mathrm{kg}$ treatment.

There was also a dose-dependent reduction in activated CD69+ T cells in the lymph
treatment

- In the skin, etrasimod reduced T cells, B cells, and eosinophils. The reduction for each subset occurred in a dosedependent manner.

There was a dose-dependen reduction in activated $\mathrm{CD} 69+$ and skin-homing CLA+ $\alpha \beta$ T cells

The dose-dependent reduction of inflammatory cells in the skin correlated with a dose-dependent improvement in ear skin inflammation and histologic scoring following FITC challenge.

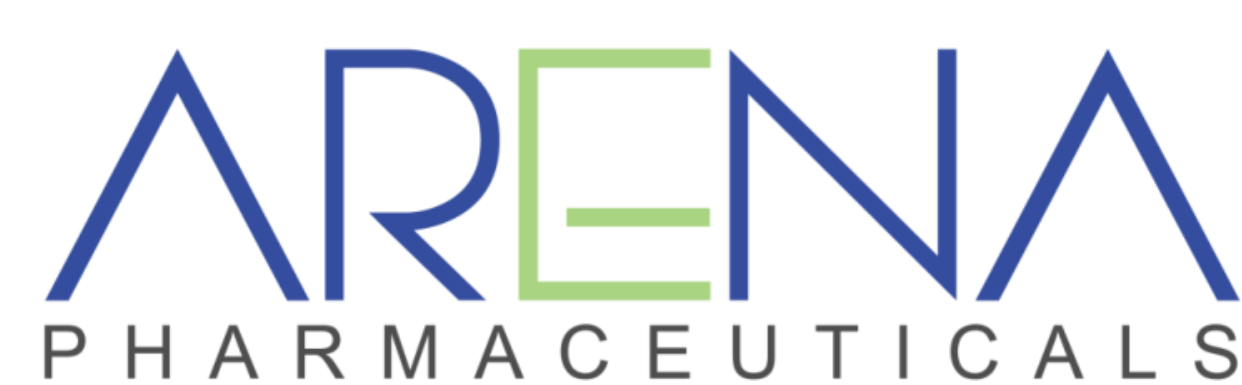

